\title{
“My Roomba Is Rambo": Intimate Home Appliances
}

\author{
Ja-Young Sung, Lan Guo, Rebecca E. Grinter, and Henrik I. Christensen \\ GVU Center \& School of Interactive Computing \\ College of Computing, Georgia Institute of Technology \\ Atlanta, GA, USA 30308 \\ \{jsung, languo, beki, hic\} @ cc.gatech.edu
}

\begin{abstract}
Robots have entered our domestic lives, but yet, little is known about their impact on the home. This paper takes steps towards addressing this omission, by reporting results from an empirical study of iRobot's Roomba ${ }^{\mathrm{TM}}$, a vacuuming robot. Our findings suggest that, by developing intimacy to the robot, our participants were able to derive increased pleasure from cleaning, and expended effort to fit Roomba into their homes, and shared it with others. These findings lead us to propose four design implications that we argue could increase people's enthusiasm for smart home technologies.
\end{abstract}

Keywords: Empirical study, home, robot, intimacy.

\section{Introduction}

As robots enter the domestic sphere in the form of pets, caretakers, and vacuum cleaners, a growing body of research argues the need to make robots fit into people's lives [5,7,12,22,31]. Yet, far fewer studies have sought to empirically understand (with the exception of [11]) whether robots change domesticity as people adopt them. In this paper, we address this omission by reporting the results of our study of one type of robot (iRobot's Roomba ${ }^{\mathrm{TM}}$ shown in Fig. 1) to learn whether, and if so, how, householders responded to their presence. What we learned suggests that people do form strong intimate attachments to these technologies.

Studying domestic robots is timely, given globally rising adoption [38], and the increasing popularity of Roomba itself as evidenced by the media ${ }^{123}$. Beyond rising numbers though, media reports also suggest that people engage in a variety of practices with robots. For example, an online video recently posted was called "Caroling Roombas" and featured three Roombas with Christmas hats programmed to sing and dance ${ }^{4}$. This story and others like it, reminded us of narratives (in books, films and comics) that have long existed that portray robots as partners in our lives. As robots enter homes, now is the right time to understand how householders adopt them and form intimate relationships. Further, we see robots playing a role in what some have described as intimate ubiquitous computing [2].

\footnotetext{
${ }^{1} \mathrm{http} / / / \mathrm{www} . w i r e d . c o m / n e w s / t e c h n o l o g y / 0,59249-1 . h t m l$ tw =wn_story_page_next1

${ }^{2} \mathrm{http} / / /$ www.usatoday.com/tech/news/robotics/2004-08-31-robotics_x.htm

${ }^{3} \mathrm{http} / / /$ www.mercurynews.com/mld/mercurynews/news/16190006.htm

${ }^{4}$ http://www.gizmodo.com/gadgets/robots/caroling-roombas-sing-dance-223938.php
} 
This paper is organized as follows. We begin by reviewing literature about intimacy and emotion within computing, robotics and psychology disciplines. After describing our methods and participants, we present three themes that spoke to the nature of the intimate relationships people formed with their Roombas. First, we learned about participants' happiness with Roomba because it helped them be cleaner and tidier. Second, people used anthropomorphic and zoomorphic qualities to engage with Roomba. Third, people demonstrated their Roomba to others, and went great lengths to change the home to accommodate it better. We conclude by discussing how intimacy can inform device adoption and help people to manage unreliability, and by presenting four implications from this study, concerning the role of form, ambiguity, accountability and support in the design of domestic ubiquitous computing systems.

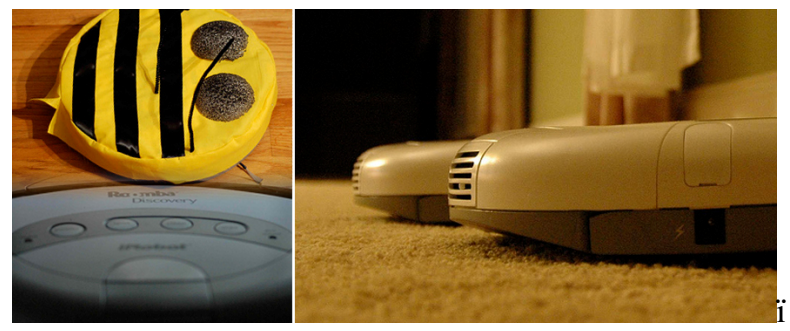

Fig. 1. Photos of Roomba Discovery ${ }^{\mathrm{TM}}$ : with and without custom-made covers

\section{Related Work: Intimate Relationships with Technology}

Various terms have been used to describe close personal relationships with technology including intimacy, affective quality, and emotional attachment. According to Bell et al. [2], intimate ubiquitous computing consists of at least one of three types of intimacy existing: a cognitive or physical closeness to technology, and feelings of intimacy between people mediated by technology. Others have argued that objects have an affective quality if they cause changes in a persons mood, emotions, and/or feelings-definitions typically used to assess intelligent agents [40]. Norman [26] uses the term emotional attachment to describe how some technologies change people's first impressions of, engagement with, and behavior. Finally, Bill Gaver's concept of ludic engagement speaks to the playful and unanticipated consequences of people's interactions with technology [14].

What all these perspectives on intimacy suggest are strong human-technology engagements. For our study, Norman's [26] definition was most useful because of its particularly detailed description of humans' relationships with non-human artifacts. That said, we decided to replace the term emotion with intimacy, because we felt that the former represented a more limited range of human responses: subjective feelings, physiological activation, and motor expressions (evidenced by [18]). Our study hypotheses, based on media accounts of Roomba usage, suggested people's responses were inter-personal and social, relying on behavior, intention, as well as emotion. This realization led us to review the social psychology literature which emphasizes 
relationships with families, partners, society and so forth [17,34]. As one social psychologist notes, intimacy is "warmth, closeness, and sharing in a relationship" [33]. Thus, in this research we broadened Norman [26] to include inter-personal and social, while retaining and using his detailed descriptions of engagement with technology to examine relationships people form with their Roombas.

Reeves and Nass [24,28] did early work on intimacy in computing, finding that people ascribe human qualities to machines such as gender, ethnicity and politeness. Other research has explored intimacy in web sites, games, and intelligent agents $[1,21,35,40]$. Despite differences in technologies, these studies have a common theme: intimacy leads to greater acceptance of technology and perceived usability. Further, Venkatesh [39], found that intimacy plays a crucial role in the acceptance of domestic computational technology. Others showed that if software or intelligent agents were designed with anthropomorphic/zoomorphic qualities, it increased system acceptance $[16,35]$. These results convinced us of the need to understand intimacyto facilitate the experience of domestic ubiquitous computing.

In robotics research we also found accounts of the potential for intimacy to exist between people and robots. Dauntenhahn's [7] survey of the social roles people would like robots to take, found that $70 \%$ of the participants wanted them as companions. Building on this study, others have designed companion robots for entertainment, assistance to the elderly and handicapped, education and everyday tasks [6,8]. Studies have shown that Sony's entertainment AIBO-with its dog-like form and AI-based software-did encourage intimacy, particularly among children who treated the robotic dog like a pet (more so than traditional stuffed toys) [12,19,23]. A study of PARO, a robotic baby seal found that it enhanced elders' quality of life in nursing homes and enhanced children's rehabilitation [20,32].

While entertainment and nursing robots are known to encourage intimate relationships, less is known about whether that's possible with service robots like Roomba. This omission is surprising given the range of service robots that exist to support vacuuming, mopping, guarding, lawn mowing and ironing. However, Forlizzi and DiSalvo's [11] seminal ethnographic study of Roomba suggests that it is possible. In addition to learning that Roombas change families' cleaning patterns and physical home arrangements, they saw people developing relationships with Roomba by naming and ascribing personality traits to the device. We built on this work in two ways. First, by focusing on intimacy exclusively, we sought to deepen the knowledge of naming and personality practices associated with Roombas, as well as to look for other signs of intimacy. Second, rather than giving Roombas to our participants, we recruited "natural" owners, to see whether these traits held for people who had adopted them outside a study setting.

In conclusion, related work suggests that people can and do form intimate relationships with technologies, including Roomba. In the remainder of this paper we report the results from our study that sought to examine how intimacy manifests itself in the case of a service robot-Roomba. In the next section, we describe our methods and participants, before turning to the results, and the design implications that arise from our findings. 


\section{Study Design}

Our study consisted of two empirical research steps: collecting written discourse from an online Roomba forum and interviewing current Roomba users who we recruited from the forum. We used the forum postings to identify Roomba enthusiasts who we followed up with for interviews. By focusing on a forum, we recognize that our data may not hold true for all Roomba owners-but we were most interested in the enthusiastic owners, the ones who had established intimate relationships with their robot. We suggest that studying this group provides unique insights into the properties and features that a robot might need to help people connect with it.

\subsection{Methods}

We began by collecting postings from a publicly accessible Roomba forumroombareview.com. We collected postings from 137 message threads, which came to a total of 760 discrete messages. Analyzing those 760 messages, we found 188 that contained at least one description of an intimacy towards Roomba (based on our revision of Norman's [26] theory of emotional attachment). In addition to confirming our hypothesis that Roomba owners (at least those on roombareview.com) had strong bonds with their robots, the postings helped us understand the types and range of practices that we thought constituted intimacy, which guided our interview design.

We also used these postings for screening participants to find those who selfexpressed (without us asking) strong ties to their Roomba. The online posts helped us customize our interview questions to fit the circumstances of each user (e.g., multiple vacuums, type of Roomba and so forth). Also, we used these online posts to confirm the data that we collected from the interviews.

After a pilot phase to refine our interview protocol, we conducted interviews with 30 people in the United States, United Kingdom, Finland, and Austria. We conducted 18 interviews via the telephone and sent 12 participants the guide via email, which they filled out and returned. Although we preferred phone interviews, we used email because some participants preferred not to use the phone citing privacy and security reasons (in the US) and being too busy (Austria). While we recognize the richness of face-to-face interviews, roombareview.com participants did not live locally to us, and we saw advantages to having international participants who allowed us to reach beyond regional and cultural differences. In each interview, we focused on three main themes. First, we asked about Roomba demographics: model types, number owned, and where and how often each robot was used. Second, we asked people whether, and if so, what they named their Roomba, whether they ascribed gender and a personality to it. Third, we asked participants to describe the advantages and disadvantages of owning and using Roomba and their opinions on potential improvements. We closed the interview by asking participants for some demographic information.

Two researchers coded the data looking for themes related to intimacy by following Friedman's et al.'s [12] description of their analysis of online AIBO forums - which was focused on understanding people's relationships with robots. Friedman et al. [12] offer five categories which emerged in people's descriptions of AIBO: technological essence, life-like essence, mental states, social rapport, and moral standing. Beginning with these categories, we conducted a top-down analysis 
of the roombareview.com postings. First, we tried to list all relevant postings under the five categories. To accommodate differences between AIBO and Roomba we extended categories to create more coherent groupings of postings. We iterated on this process when analyzing the interview data. The categories from the online posting analysis guided our top-down analysis and led to the final set of themes. Our analysis of the interviews relied on the phone interviews, because the email replies did not contain as much overall detail. However, the emails did provide supplementary data when counting frequencies (e.g. how many people named their Roomba). Hence, the quotes and observations described in this paper mainly come from the phone interviews.

We present our results organized around three themes that spoke to the nature of the intimate relationships people formed with their Roombas. First, people spoke of happiness with Roomba because it positively changed their attitude toward cleaning. Second, people used anthropomorphic and zoomorphic qualities to engage with Roomba. Third, people valued their Roombas and consequently took pleasure in demonstrating it to others and by changing the home to accommodate it better.

\subsection{Participants}

Among our 30 participants, all owned at least one Roomba: 18 owned just one, nine owned two, and the remaining three owned three, five, and nine (with two more being shipped) respectively. The average length of ownership among our participants was 10 months, varying from one week to five years.

Our sample, to the best of our knowledge, was fairly gender balanced with 16 men and 14 women who ranged in age from 27 to 76 years. Six participants were in their 20 's and seven were in their 30's, while 12 participants were in their 40's. We had one participant in their 50's and 2 participants each in their 60's and 70's. Eight of our participants were single, and four of those people owned pets. The remaining 22 participants came from households where they lived with a spouse or a partner. In these households, 8 families did not have children or pets, 5 families had children but no pets, 5 families had both children and pets, and 4 had pets but no children.

Our participants had a wide range of technical expertise based on the self-reports of their education, professional backgrounds, and their experience with technologies (we asked about latter to see if any of our participants were self-taught technology enthusiasts). Twenty-six of the 30 participants had college degrees, while 13 had majored in science and engineering related degrees, such as mechanical engineering, computer science and electrical engineering. Our participants had diverse professions including lawyers, full-time homemakers, software engineers, a nurse and a hair salon owner. Finally, 13 households owned robots other than Roomba, such as Scooba, AIBO, Lawn Mower and humanoid robot toys (i.e., Robosapience).

What all of our participants shared in common was an enthusiasm for their Roombas. We recognize that this may not hold true of all Roomba users although the thriving businesses surrounding Roomba such as the production of costumes suggest a bigger market than the self-identified enthusiasts of the Roombareview.com could sustain. That said, we were intrigued by this sample of people who had managed to develop a strong bond with their Roombas. In particular, we wanted to learn what it took to achieve the bond and what it possibly means for ubiquitous computing. 


\section{Manifestations of Intimacy}

In this section, we describe findings that show how our participants established and maintained intimate relationships with their Roombas. Specifically, we present themes focused on changing attitudes towards cleaning, using life-like associations to engage with Roomba, and valuing the robot enough to demonstrate it to others and change the home to accommodate it better.

\subsection{Feeling Happiness Towards Roomba}

Some social psychologists [17,34] argue that intimacy increases happiness and satisfaction with life. We found this type of intimacy for some of our participants. They were elated that house cleaning no longer required manual labor, and even described vacuuming as changing "from a drudgery to a happy thought". We sought to understand what might have caused this change in perspective towards cleaning, and turned to sociological literatures on housework [29,30]. These literatures argue that as house size has increased and maid/servant labor declined, the women responsible for cleaning (increasingly engaged in paid-labor themselves) found themselves in a dilemma. Either they took more time to clean, or they simply cleaned less-leading to negative feelings associated with vacuuming including guilt [30].

By contrast, and possibly one reason for happiness, our participants described a noticeable increase in their standard of cleanliness since adopting Roomba. Participants told us that they could see that there was less pet hair and dust, which made them feel confident and comfortable inviting guests into their house. In addition to simply being motivated to run Roomba more frequently than to vacuum, our participants also spoke of a desire to keep Roomba running smoothly which itself involved being tidy. For instance, three of our participants told that they tended to pick objects up off the floor because small items could harm Roomba. Another householder expressed happiness because his children now picked their toys up off the floor voluntarily before going to sleep, knowing that Roomba would clean the floor early in the morning. Further, he described that Roomba helped the whole family become neater. In his words:

\section{When we know the Roomba is going to be cleaning the next day, we don't want that stuff to get in the way so we tend to put things away more. I think its kind of forcing us to be neater people.}

The happiness generated by Roomba also seemed to compensate for the extra work required from the robot. Like other domestic technologies [6,7], Roomba did not save householders' time and labor because it both took time, and also created monitoring and maintenance tasks. Participants described that cleaning with a Roomba took longer than with a traditional vacuum cleaner-albeit in smaller chunks-because of the need to move the machine around the rooms of the house. They also described new cleaning tasks: monitoring and rescue. For example, participants told us about their Roombas getting stuck underneath chairs or trapped in the bathroom. Indeed some householders described monitoring the robot in order to "rescue" it from danger.

This monitoring and rescue work also generated surprising responses among our participants. For example, instead of complaining about the extra work, they often 
told us how they "worried" and "felt sorry for" the robot when it was in danger or had gotten stuck. They also characterized the monitoring process as a form of entertainment, watching and wondering whether Roomba would avoid obstacles. Cleaning almost sounded like a spectator sport.

Another new task was to clean the robot itself. Participants described how brushes, bins and motors needed cleaning to remove the fine dust that might corrupt the sensors and affect Roomba's function. The majority of our participants performed this (approximately 15 minute) task most times they used the robot. This task was the only one that our participants complained about having to do, but unilaterally they preferred this task to that of manual cleaning.

For some, the happiness and joy of using Roomba changed their entire outlook on cleaning. Some preferred and even insisted that what they did with the Roomba should not be described as vacuuming. For example, a male participant explicitly told his friends that he was playing with a robot rather than saying, "I am vacuuming my house". Another participant shared his experience of getting upset when he saw Roomba being advertised as a vacuum cleaner in a store. His argument was that the label "vacuum cleaner" does not provide an appropriate description of Roomba. Interestingly we note that it was men who were more likely to characterize experiences with the Roomba as being something unlike vacuuming, an activity typically associated with women. However, we do not have sufficient evidence to fully explore the gendered implications of these comments.

Roomba seemed to make our participants very happy. They recounted experiences monitoring, rescuing and watching Roombas. Also, they talked about the positive benefits of a cleaner house and described how they enjoyed seeing other and new householders participating in the cleaning activities. As one participant put it, Roomba seems to sit "somewhere between a pet and a home appliance" which we turn to in the next section.

\subsection{Lifelike Associations and Engagement with Roombas}

Breazeal [4] argues that one form of affection that people can show to robots involves ascribing anthropomorphic/zoomorphic characteristics. We saw ample examples of this in our study. We conjecture that people's ability to anthropomorphize and zoomorphize helps them value Roomba high enough to treat the robot as a trusted and dear object. For example, one of our interview questions asked, 'what does Roomba mean to you?' Responding to that question, we found that people expect the domestic robots to become companions (also observed in [7]). The majority of our participants described Roomba as some form of household companion with lifelike properties, such as "a helpful assistant", "a pet-like being" and "a valuable family member". Perhaps somewhat extremely, three participants actually listed their Roombas (including their names and ages) as family members when we asked them to provide demographic information about members of their household.

Another prevalent anthropomorphism was the description of personality. Eighteen participants felt that Roomba had intentions, feelings, and unique characteristics. One participant who owns two Roombas and one Scooba felt that each unit had a unique personality although he was well aware that technology had not advanced that far: 
Mine, I feel they are different... For me how they look, each one has certain different behavior. And I know definitely they have a same firmware or a similar firmware so the difference should not be much but ah, for example, my discovery, he's more crazy. He runs into things and sometimes and goes into different places he should not be going to. And the scheduler he's more like refined. He knows what he's doing.

Like this participant, Norman [27] argues that movement helps people perceive robotic objects as lifelike. Most of our participants latched onto the randomness of Roomba's movement-generated by an algorithm designed to promote Roomba's passage across all sections of the space being cleaned-as being something that triggered an expression of personality. Some people told us that behavior such as getting stuck on particular furniture, constantly missing a certain spot, or bumping into the same wall was part of their Roomba's personality. Our participants saw these behaviors as different from the routine movements of machines, and consequently it seemed akin to the unforeseen actions of humans. Participants also used sound as another signifier of personality, using descriptions including "energetic and spirited". In actuality, Roombas make a series of sounds to communicate the start and end of their cleaning cycles, as well as communicating success, failure and repairs required. None of these sounds are human (taking the form of beeps instead).

Breakdown and repair were other occasions for people to anthropomorphize about their Roombas. After sending Roomba to be repaired, some participants expressed surprise at their own grief, describing Roomba being "dead, sick, or hospitalized". For example:

We did a non-warranty exchange and it was emotionally...it's interesting that 'Spot' was not actually just a robot; it was a....we had some real reservation knowing that we are going to send this one back to the company and we are going to get a different one back.

Scherer [15] argues that intimate feelings determine whether people will engage in social interaction. In our study, we learned that people communited with their Roombas by greeting, praising and reprimanding them. For example, one participant described how he reprimanded his Roomba and Scooba when they nearly collided in the kitchen, and how much he was surprised by his own reaction that he treated robots as somehow alive and able to respond to and absorb his admonishment. This echoes other research that shows that people apply social norms and rules to intelligent technology [24,28,31]. In our study, the social norms that most frequently arose for our participants who viewed Roomba as life-like were giving names, a gender, and a status within the family to the robot.

Surprisingly to us, 21 out of 30 householders told us that they gave names and nicknames to Roombas. Although many of our participants could not explain their motivation behind this action, they reported that it seemed natural, and that Roomba "deserved" a name particularly considering the benefits the robot provided. Some people also explained that they need a name to call Roomba since it was a frequent topic of conversation among family members, or as a way to distinguish a particular unit among multiple robots.

In all cases, naming involved much thought and consideration, and often resulted in explicit decoration or engraving onto the firmware itself. In one household, the 
family members put their favorite names into a hat and selected a winner as a way of deciding between competing entries. Other householders decided on a name before the Roomba arrived. Many people draw on their favorite sci-fi or other movie characters. We also learned that people changed the names of their Roombas over time. For instance, one household changed the name of their Roomba from Robocop to Aarnold (not "Arnold") after the Terminator because the latter seemed to be a better fit to the personality of their robot. This shows that the householders evolve intimate relationship with their Roomba. In another house where they could not find a name that everyone liked, Dad had called it Fred and the children had called it R2D2 (after Star Wars character) while Mother used both names, calling it by the preferred name of the person that she was talking with.

However, naming was not always a barometer of intimacy. One of our participants told us she did not name her Roomba because she felt the name "Roomba" already expressed the nature and personality of the robot well enough. Instead — and in a sign of what we would suggest is intimacy-she typically referred to it in more sentimental forms. For example, in her words:

\section{I can't imagine not having him any longer. He's my BABY!!... When I write emails about him which I've done that as well, I just like him, I call him Roomba baby...He's a sweetie.}

Also, reflected in the quote above was an ascription of gender to the Roomba. In fact, 16 participants told us that they talked about Roomba in gendered terms. While we saw both genders being used in online discourse, all of our interviewees described Roomba as male. While some participants were very careful not to address Roomba as "it" because of their sense that Roomba was more than just a machine, most of the people who used "he" interchanged that pronoun with "it".

Our participants also explained how they had decided Roomba's gender. They described its masculinity as coming from its shape, color and a preconception of male-dominance in the realms of technology and machinery. The last reason, that of ascribing gender based on a sense that men have dominated the history of technology — and perhaps especially in the area of robotics - speaks to what we might term the "genealogy of technology." By technological genealogy we mean that people seem to make sense of new technologies by drawing on their historical knowledge of similar objects. We also found some more unusual reasons. The gender of one Roomba in this study came from the person previously in charge of the manual vacuuming, a man. By contrast, two female participants explicitly told us that they referred to Roomba as "he" because they liked the idea of having a man do the cleaning for them.

In conclusion, our participants engaged their Roomba by ascribing it life-like and social characteristics. Many saw their Roombas as somehow cognitive and physical as well as having a personality, name and gender. This in turn helped them engage sufficiently so that they could talk and write about it, through which we argue, they formed a relationship with their robots.

\subsection{Valuing Roomba: Promoting and Protecting It}

In this section, we discuss another dimension of the intimate relationship that people formed with Roomba-one associated with feeling that it was of such value that they 
wanted to promote to their friends and colleagues, and also protect it by making it welcome in their homes. Our participants demonstrated how valuable they felt Roomba was by telling us how they recommended it to other people. All of our participants have shown Roombas to visitors in their homes, irrespective of whether their guests are adults or children, which extensively implicates whether or not they have the purchasing power. Also, they have extolled the virtues of the Roomba to close friends and their extended family. For example, one participant told us about writing email and talking about Roomba on the telephone to friends and family, and many have even purchased Roombas as gifts.

In addition to encouraging others to purchase Roombas, some of our participants had made their own acquisition after seeing it in someone else's house. For example, two female participants purchased their Roombas after they saw the quality of its performance in their neighbor's home. Another participant said that she received the robot as a gift from her adult son. Our participants lead us to believe that Roomba adoption by word of mouth is how a healthy percentage of people come to own these technologies. One participant described his own promotional work:

(I have taken the Roomba to my parents' house to show how well it works) Anyway, my parents ended up buying 2..., their next-door neighbor bought one, and my aunt bought one. Now my brother is looking to buy one.

Beyond local promotion, particularly within families, we also encountered owners who had taken their Roomba to work and to their vacation homes. In addition to potentially using it, particularly in the latter setting, these participants described showing it to their colleagues and holiday neighbors. Our Finnish participant worried about sales in Finland, and made a video of her Roomba, and sent to her local distributor to help them promote the technology. Another participant offered Roombas as prizes in a business-based competition she ran, for which she received a number of entries.

The strength of the relationship that our participants felt with their Roombas not only encouraged them to promote Roomba to others, but also motivated them to modify their living environment to accommodate the floor vacuum. Twenty-seven of the 30 households we spoke with had made changes to their houses to accommodate Roomba. This is known more widely as "Roombarization".

Roombarization consists of a variety of activities. For example, participants described raising the wires off the floor in order to prevent Roomba from "choking" on them. Others talked about moving furniture around so that Roomba could navigate through their house without getting stuck. Some of our participants learned Roombarization techniques through trial and error after watching Roomba navigate and get caught, such as raising the height of chairs to let Roomba pass underneath. But, surprisingly, some people configured their homes prior to Roomba's arrival.

In a few cases, we learned that Roombarization could bring drastic changes to the home. One of our participants told us that she threw away her rug in the living room because her Roomba kept "getting frustrated" with the length of the shag, getting it caught in its brushes. Another participant taped down the entire tassel on the carpet every time he ran the robot. Also, we had a participant who replaced the old refrigerator with a new one that had enough space underneath for Roomba. 
Although these last descriptions may seem somewhat extreme, the majority of our participants had done something to accommodate Roomba. Roombarization appears to be a vital part of the adoption process, and our participants all tried hard to make their Roombas fit into their domestic environment. Many reported spending time following Roomba during its initial uses to understand how and where they could make changes that would better suit the robot. The intimacy that was built during this process became apparent when a participant raised his concern about taking Roomba to un-Roombarized environment.

\section{I brought mine ... when I visited my parents soon after I bought it so they could see if they wanted one. I ended up being very protective of it since there were a lot of things in their house that it could get choked on or stuck on.}

In this, and the last two sections, we have argued that the Roomba owners in our study had developed an intimate attachment to their Roombas. These attachments manifested themselves in a variety of ways. People were willing to take on extra cleaning and maintenance work in order to make Roomba function effectivelyreplacing one form of cleaning for another. Also, our participants saw Roomba as more than an appliance, and consequently were motivated to ascribe personality, name, and give their robot a gender. Finally, they wanted to share their experience with Roomba with others, allowing other people to benefit and share the joys of ownership.

\section{Discussion: The Role of Intimacy in Domestic Appliances}

Scholars argue that in human-human relationships intimacy helps people to be happier and healthier [17]. Our study suggests, as others have found for other types of computing and robots outside of the service domain, that people seem to be able to form intimate relationships. In this section, we discuss how those relationships may inform device adoption and help people to manage unreliability-potentially useful attributes for ubiquitous computing technologies more generally.

\subsection{Visibility and Device Adoption}

Within ubiquitous computing and related communities, researchers have begun discussing what it means for technology to disappear into household routines. Some researchers [37] question whether perceptual disappearance is the only criteria for success integration, but others [10] suggest that visibility of a technology's location can help adoption. Our study also speaks to questions of visibility and its relationship to domestic routines and device acceptance.

Our participants described the highly visible presence of Roomba in their homes. They spoke of loud operational noises generated by its movement, and of light and sound patterns generated when Roomba had information to communicate. Additionally, as an autonomous moving device, Roomba was inclined to appear in the field of view of our participants, their family and pets, as it moved around the home 
cleaning. Indeed, one participant who lived alone told us how he felt a stronger connection to his Roomba than his Scooba-iRobot's mopping robot-precisely because they tended to share the same space. By contrast, his Scooba tended to work in parts of the house that he didn't spend much time in, such as the kitchen and bathroom. In other words, high visibility of Roomba brought comfort to our householders, which led to easier adoption of the robot.

The adoption of Roomba also changed domestic routines (also seen by [11]). In addition to the cleaning routines, other activities took place, such as making time to name, ascribing gender and personality traits to the device, and talking about it within the family (as well as outside). This was in contrast with other studies of adoption, particularly those associated with adoption of white-goods (refrigerators, cookers, non-robotic vacuum cleaners) where we generally saw an emphasis on how much time and how frequently people engaged in activities associated with these devices. More broadly, they were coupled to assessments of the ongoing labor associated with housework. By comparison, our study of Roomba yielded much more information about social routines with the device rather than tasks performed with the device. Instead of counting the hours of housework, people talked to us about the complexities of naming their vacuum cleaner. Further, we would argue that this suggests an adoption process that is not only different from that associated with conventional technologies (even potentially computational ones) but also perhaps more enjoyable and rewarding.

Clearly, future research remains to explore the possibilities for adoption when people form an intimate relationship to an object. However, our study suggests that the presence of intimacy opens up new possibilities for how people will incorporate this technology into their home routines. We also suggest that intimacy might be a means to explore artful systems [36] - those that couple their support to household projects in artful rather than strictly functional-as facilitators of device adoption.

Finally, while routines have received considerable attention within the ubiquitous computing community, the nature of intra-family relationships and their affect on technology adoption has been less discussed. Family relationships came up throughout our study; with participants describing how some people adopted Roomba before others. For example, some participants told us that they were initially skeptical when their spouses and sons brought Roomba home. Indeed, one participant described it as an "expensive toy" for her husband. However, after the husband ran the robot a few times, she told us that on seeing the amount of dust that it picked up, she decided that it was actually a useful appliance. Further, within a year, that household added two more robots - another Roomba and a Scooba.

An interesting possibility that we raise here is that while accounts of vacuuming suggest that it is an activity that belongs to someone, the arrival of Roomba creates opportunities for a reallocation of responsibility. More generally, many of our participants articulated a sense of value that the robot created for them in their cleaning routines. Even though it required Roombarization, the use of Roomba changed how and what was involved in vacuuming, and people spoke of it in positive terms. Adoption of the device was not just functional, but also included being a helpful assistant, entertainment, a pet-like being, and a valuable member of the house. 


\subsection{Reconsidering Reliability}

In their paper on challenges for domestic ubiquitous computing, Edwards and Grinter [9] introduce reliability as an issue for this community. Specifically, they argue that ubiquitous computing systems will likely need to be highly reliable in order to meet householders' expectations about the systems they have in their home. Our study showed that while Roomba users hoped that their robot would be reliable, they did not expect it to work flawlessly. Further, they took on extra work to increase Roomba's odds of working well. For example, almost all the people we interviewed and surveyed opened up Roomba and cleaned its motors and brushes frequently-in some cases each time they ran it. They explained to us that they did this work to avoid the "Circle Dance"-Roomba going around and around in the same spot—which happens when the sensors are clogged by dust.

Day-to-day then, our participants tolerated Roomba's potential for flaws, although they tried to mitigate the possibility of failure through preventative measures. In addition to taking care of Roomba, we saw lots of other examples of day-to-day measures designed to keep the robot working. People picked up small items up off the floor to protect Roomba when it was out on its next "mission", We heard that this was not just associated with the person in charge of running Roomba, but in many cases an activity that other householders participated in. Indeed, people reconfigured their homes-Roombarization-also to increase the odds that Roomba would complete its mission successfully.

So, we asked our participants whether this work of picking things up was a burden. Surprisingly, we heard from people that this work of tidying was a token of their appreciation for the hard cleaning work that their Roomba did. Some people even termed this feeling as being the least that they could do given how hard they worked their Roomba. This raises an interesting question-and something we would like to explore further-about the relationship between Roomba owners and their vacuum cleaner. Specifically, the almost guilt-like quality to this relationship makes us wonder whether it turns on a master-servant dynamic, something that might make many people today feel uncomfortable. More generally, we think that intimacy-that sense of a relationship - helps engage people in doing work to change their routines to accommodate technology. Further, this stands in marked contrast with previous research that has argued that technology succeeds when it is absorbed into existing patterns of activity.

We also learned about a different type of reliability - that this happens over the long-term. For instance, we had a female participant who bought her first Roomba when iRobot launched its initial product (about 5 years ago). Early Roombas, she explained, did not last long due to some technical problems. Yet, she told us that she kept purchasing replacements-instead of being frustrated and ceasing to use this product. Other participants shed some insight into why this might be the case. For example, two other women (although we are not sure whether this particular type of relationship is gendered) explained that "I can never not have one" and more extremely perhaps "I will always have one until I die". Our data suggests that forming

\footnotetext{
${ }^{5}$ Another example of a technology's genealogy, iRobot describes Roombas cleaning cycle as a "mission" speaking to the origin of this robot: the military.
} 
a strong bond with the technology is possible even in the face of technical issues, and further might lead people to persist in adoption despite problems.

\section{Design Implications}

Throughout this paper, we have suggested that there are advantages when people can develop intimate relationships with technology by which we mean deep ties that inspire and engage people to interact with and accommodate a system. In addition to describing the dimensions of this intimacy that we observed in our research, we discussed how intimacy and adoption and reliability interact. In this section, we wish to explicitly raise some of the design implications that intimacy raises.

\subsection{Form Follows Function?}

In the last decade, a considerable amount of research has been undertaken to explore the possibilities presented by intelligent agents. Whether built in hardware or software, this research has typically assumed that mimicking lifelike objects such as humans and animals offers advantages. This assumption has been reinforced through confirmatory empirical research. For example, the laboratory study of Kismet, a robot that can express human emotions, found that the lifelike form yielded stronger emotional responses [4].

However, other research (e.g. [35]) raises an important concern that using a lifelike form carelessly can decrease people's intimate responses to the technology. In our study, we complement but extend this research by showing that a non-lifelike form can also engender strong attachment. Despite being designed with cleaning in minda low round object that travels underneath furniture to maximize the vacuumingRoombas generated strong responses among our participants.

Further, we even found evidence that lifelike forms might be inappropriate for domestic technologies. For example, one of our participants told us that while he wanted to buy a Sony AIBO, his wife refused to have a "fake dog" in their home. He told us that she felt much more comfortable with non-lifelike robotic forms. Many more participants spoke enthusiastically about Roombas shape; because of its perceived appropriateness for the job it was designed to do-clean. And, of course, people were always able to dress and name their robots to "add" lifelike properties. Minimally, we suggest that a humanoid or animalistic form may not be required to generate strong responses_-which in turn opens the design space of possibilities.

\subsection{Intimacy Through Ambiguity}

One interpretation of ambiguity for ubiquitous computing is a degree of confusion that could lead to error [9]. The arguments for simplicity, ensuring that householders can control their smart homes-and through their lives-abound. By contrast, Gaver voices different vision of ambiguity as a powerful resource that can promote close personal relationships fueled by curiosity and engagement [13].

This study supports Gaver's argument. Our participants described delight in following Roomba, trying to figure out its algorithm and examining it to learn more about how the robot worked. Also, like Forlizzi and DiSalvo [11], our participants 
told us that they experimented with Roomba, particularly when they first owned it. For example, one man put dust in front of his new Roomba to see whether it really vacuumed. Others put multiple Roombas together to see how they would interactalthough Roomba does not do collision detection. And, we even heard people describing how they let their children and pets ride on their Roomba! We suggest that ambiguity has the potential to inform the design of engaging smart home appliances, perhaps even increasing their sense of smartness, by giving them characteristics that are hard for owners to understand. Further, it puts an interesting spin on the question raised by Edwards and Grinter [9]: how smart does smart home technology have to be, if people enjoy ambiguity and through that develop a commitment to a particular technology? In conclusion, we suggest that exploring ambiguity further, and potentially adding elements of the ambiguous have much to offer in the design of ubiquitous systems for the home.

\subsection{Intimacy Through Accountability}

Researchers like Bell [3], Norman [25], and others argue that technologies should make their actions accountable. In other words, people should be able to see into a technology's process to understand how a system got from start to finish. Our participants told us that they liked being able to see how Roomba worked. For example, householders ran Roomba multiple times per day to check how much dust Roomba picked up. Many admitted astonishment that Roomba picked up lots of dirt (possibly from areas difficult to get at with a traditional vacuum cleaner) when first used. This astonishment has evolved, over time and with regular use, to a sense of comfort and relief that the amount of dust decreased. Most spoke explicitly about how seeing the dust made them aware of the fact that Roomba was really cleaning their homes, and they spoke of valuing the robot's performance.

The exploration of state as a mechanism for accountability, we suggest, has much to offer in the design of domestic appliances. In addition to showing the current state of the system, Roomba's ability to "show" how the dirt situation was changing over time, provides an example of how people enjoyed being able to see change over time. We recognize however, that achieving these trades off against the potential for ambiguity is a topic open for further exploration.

\subsection{Intimacy Through Support}

Scholars have had a long-standing interest in the social implications of domestic technology, studying among other things such as privacy, gender, ownership patterns and societal expectations of usage $[9,36,39]$. Our study suggests that for some, Roomba changed cleaning from an individual act to a household activity with people participating in aspects of using, maintaining and caring for Roomba. Further, it was clear that cleaning was a topic of conversation by using the names in discussion and showing Roomba to people outside the home.

One significantly change, we heard, was the increase of support. For example, a woman told us that she felt comfortable to invite her friend with an infant over because the floor was hygienic enough for the baby to crawl on. Roomba supported her by helping her have a house that was hygienic. Other people told us that Roomba 
helped them by doing work that they couldn't easily do, which was pronounced among people whose physical injuries made cleaning difficult. Finally, one participant described support that comes through independence. In this case, he was disabled, and by using Roomba he no longer needed to ask his mother to clean for him. We suggest that ubiquitous computing in its agenda of providing technologies to support treatment and care, should consider the implications of support not just on the individuals that are affected, but also on the ways that they will in turn influence the relationships between technology and people.

\section{Conclusions}

In this paper, we built on and extended the seminal research conducted by Forlizzi and DiSalvo [11] — who reported engagement between people and service robots-by exploring the nature of these intimate human-robot relationships. Our goal, in exploring these relationships by people who have formed them "in the wild", was to understand what the strength of those bonds had to offer ubiquitous computing researchers interested in providing householders with rich, meaningful, engaging, and long-term relationships with the systems.

We found three themes that spoke to the nature of the intimate relationships people formed with their Roombas. First we learned about how householders feel happiness toward Roombas for helping them become neater. Second, people used life-like associations to engage with Roomba. Third, people valued Roomba enough to promote to others and to change the home for better accomodation. We conclude by discussing how intimacy can inform device adoption and help people to manage unreliability, and by presenting four implications from this study concerning the role of form, ambiguity, accountability and support in the design of domestic ubiquitous computing systems.

We offer our findings as the beginning of what we hope will be a much longer discussion within this and other communities that focus on understanding the depth and richness of the ubiquitous computing experience. Further, as the service robot industry continues to grow, and people increasingly adopt robots to help them manage aspects of their housework, we see the need to consider robots as a feature of the smart home of the future, and therefore a part of the ubiquitous computing agenda.

Acknowledgements. We thank Roombareview.com users and Nikolai Telsa for sharing rich and valuable experiences. Also, we thank work2play lab, Kris Nagel, Ken Anderson, and the anonymous reviewers for their constructive guidance and enthusiasm for this topic. This work is supported by the NSF CNS \#0626281.

\section{References}

1. Axelrod, L., Hone, K.: E-motional Advantage: Performance and Satisfaction Gains with Affective Computing. In: CHI '05 extended abstracts on Human factors in computing systems, ACM Press, Portland, OR, USA (2005)

2. Bell, G.: Intimate Ubiquitous Computing. In: Proceedings of Ubicomp 2003, ACM Press, New York (2003) 
3. Bell, G., Kaye, J.: Designing Technology for Domestic Spaces: A Kitchen Manifesto. Gastronomica 2(2) (2001)

4. Breazeal, C.: Affective Interaction between Humans and Robots. In: Kelemen, J., Sosík, P. (eds.) ECAL 2001. LNCS (LNAI), vol. 2159, Springer, Heidelberg (2001)

5. Breazeal, C.: Robots in Society: Friend or Appliance? In: Agents99 Workshop on Emotion-based Agent Architecture, Seattle, WA, USA (1999)

6. Christensen, H.I.: Intelligent Home Appliances. Springer Tracts in Advanced Robotics (STAR) 2003(6), 319-330

7. Dautenhahn, K., et al.: What is a Robot Companion - Friend, Assistant or Butler? (2005)

8. Decuir, J.D., et al.: A Friendly Face in Robotics: Sony's AIBO Entertainment Robot as an Educational Tool. Comput. Entertain. 2(2), 14-14 (2004)

9. Edwards, W.K., Grinter, R.E.: At Home with Ubiquitous Computing: Seven Challenges. In: Abowd, G.D., Brumitt, B., Shafer, S. (eds.) Ubicomp 2001. LNCS, vol. 2201, p. 143. Springer, Heidelberg (2001)

10. Elliot, K., Neustaedter, C., Greenberg, S.: Time, Ownership and Awareness: The Value of Contextual Locations in the Home. In: Beigl, M., Intille, S.S., Rekimoto, J., Tokuda, H. (eds.) UbiComp 2005. LNCS, vol. 3660, Springer, Heidelberg (2005)

11. Forlizzi, J., DiSalvo, C.: Service Robots in the Domestic Environment: a Study of the Roomba Vacuum in the Home. In: Proceeding of the 1st ACM SIGCHI/SIGART conference on Human-robot interaction, ACM Press, Salt Lake City, Utah, USA (2006)

12. Friedman, B., Kahn Jr., P.H., Hagman, J.: Hardware Companions?: What Online AIBO Discussion Forums Reveal About the Human-Robotic Relationship. In: Proceedings of the SIGCHI conference on Human factors in computing systems, ACM Press, Ft. Lauderdale, Florida, USA (2003)

13. Gaver, W.W., Beaver, J., Benford, S.: Ambiguity as a Resource for Design. In: Proceedings of the SIGCHI conference on Human factors in computing systems, ACM Press, Ft. Lauderdale, Florida, USA (2003)

14. Gaver, W.W., et al.: The Drift Table: Designing for Ludic Engagement. In: CHI '04 extended abstracts on Human factors in computing systems, ACM Press, Vienna, Austria (2004)

15. Hadden, J., Shupe, A.: Televangelism in America. Social Compass 34(1), 61-75 (1987)

16. Herbsleb, J.D.: Metaphorical representation in collaborative software engineering. In: Proceedings of the international joint conference on Work activities coordination and collaboration, ACM Press, San Francisco, California, United States (1999)

17. Higgins, E.T., Kruglanski, A.W.: Social Psychology: Handbook of Basic Principles, pp. 523-557. Guilford Press, New York (1996)

18. Izard, C.E.: Human Emotions. Plenum Press, New York (1977)

19. Kahn, P.H., et al.: Robotic Pets in the Lives of Preschool Children. In: CHI '04 extended abstracts on Human factors in computing systems, ACM Press, Vienna, Austria (2004)

20. Kidd, C.D., Taggart, W., Turkle, S.: A Sociable Robot to Encourage Social Interaction Among the Elderly (2006)

21. Mahlke, S., Minge, M., Thring, M.: Measuring Multiple Components of Emotions in Interactive Contexts. In: CHI '06 extended abstracts on Human factors in computing systems, ACM Press, Montreal, Qubec, Canada (2006)

22. Marti, P., et al.: Engaging with Artificial Pets. In: Proceedings of the 2005 annual conference on European association of cognitive ergonomics, University of Athens, Chania, Greece (2005)

23. Melson, G.F., et al.: Robots as Dogs?: Children's Interactions with the Robotic Dog AIBO and a Live Australian Shepherd. In: CHI '05 extended abstracts on Human factors in computing systems, ACM Press, Portland, OR, USA (2005) 
24. Nass, C., Moon, Y.: Machines and Mindlessness: Social Responses to Computers. Journal of social issues 25(1), 81-103 (2000)

25. Norman, D.A.: Design of Everyday Things, Currency Doubleday (1989)

26. Norman, D.A.: Emotional Design: Why We Love (or Hate) Everyday Things. Basic Books, New York, USA (2004)

27. Norman, D.A.: Robots in the Home: What Might They Do? Interactions 12(2), 65 (2005)

28. Reeves, B., Nass, C.: The Media Equation. Cambridge University Press, New York, USA (1996)

29. Robinson, J.P., Milkie, M.: Dances with Dust Bunnies: Housecleaning. In: America. American Demographics 19(1) (1997)

30. Robinson, J.P., Milkie, M.A.: Back to the Basics: Trends in and Role Determinants of Women's Attitudes toward Housework. Journal of Marriage and the Family 60(1), 205218 (1998)

31. Scopelliti, M., Giuliani, M.V., Fornara, F.: Robots in a Domestic Setting: a Psychological Approach. Journal Universal Access in the Information Society 4(2) (2005)

32. Shibata, T., et al.: Human Interactive Robot for Pscyhological Enrichment and Therapy. In: AISB'05 Social Intellignece and Interaction in Anismals, Robots, and Agents, Hatfield, UK (2005)

33. Sternberg, R.J.: A Triangular Theory of Love. Psychological Review 93, 119-135 (1986)

34. Sternberg, R.J., Grajek, S.: The Nature of Love. Journal of Personality and Social Psychology 47, 233-464 (1984)

35. Suganuma, T., et al.: Bridging the E-gaps: Towards Post-Ubiquitous Computing. In: 20th International Conference on Advanced Information Networking and Applications (AINA) (2006)

36. Taylor, A.S., Swan, L.: Artful Systems in the Home. In: Proceedings of the SIGCHI conference on Human factors in computing systems, ACM Press, Portland, Oregon, USA (2005)

37. Tolmie, P., et al.: Unremarkable Computing. In: Proceedings of the SIGCHI conference on Human factors in computing systems: Changing our world, changing ourselves, ACM Press, Minneapolis, Minnesota, USA (2002)

38. U.N., World Robotics, 2005, United Nations Economic Commissions for Europe and International Federation of Robotics, Frankfurt, Germany (2005)

39. Venkatesh, V.: Determinants of Perceived Ease of Use: Integrating Control, Intrinsic Motivation, and Emotion into the Technology Acceptance Model. Info. Sys. Research 11(4), 342-365 (2000)

40. Zhang, P., Li, N.: The Importance of Affective Quality. Commun. ACM 48(9), 105-108 (2005) 